\title{
Qualidade de sementes de azevém anual e seus impactos no estabelecimento inicial em diferentes densidades de semeadura
}

\author{
Ternus, R.M ${ }^{1,3}$; Cavalcante, J.A. ${ }^{2}$; Weiss, A.C. ${ }^{1}$, Folquini, P.S. ${ }^{1}$, Philippi, E. ${ }^{1}$ e Zanini, G.D. ${ }^{1}$
}

'Centro Universitário Barriga Verde (UNIBAVE). Orleans. SC. Brasil.

2Universidade Federal de Pelotas (UFPEL). Programa de Pós-graduação em Ciência e Tecnologia de Sementes FAEM. Rio Grande do Sul. RS. Brasil. ${ }^{3}$ Companhia Integrada de Desenvolvimento Agrícola de Santa Catarina (CIDASC). Tubarão. SC. Brasil.

PALAVRAS CHAVE ADICIONAIS

Lolium multiflorum Lam.

Germinacão.

Pureza.

Manejo de pastagens.

\section{RESUMO}

Um dos problemas que envolvem a formação de pastagens de inverno no Sul do Brasil é a variação na qualidade das sementes de espécies forrageiras disponíveis no comércio, o que resulta na comercializacãa de sementes de baixa qualidade. Neste sentido, objetivou-se avaliar a qualidade de lotes de sementes de azevém anual (Lolium multiflorum Lam.) comercializadas no Sul de Santa Catarina (Brasil), nas safras 2013, 2014, 2015 e 2016, bem como seus efeitos no estabelecimento inicial em diferentes densidades de semeadura. As sementes coletadas foram oriundas do excedente de coletas oficiais de amostra de sementes, realizada por Fiscal Estadual Agropecuário em estabelecimentos comerciais. A qualidade das sementes foi avaliada como variável resposta por meio da pureza física, teste de germinação e número de sementes de outras espécies. Para avaliação do estabelecimento inicial em diferentes densidades de semeadura foi utilizado um delineamento experimental em blocos completos casualizados, em esquema fatorial, $2 \times 4$, com quatro repetições. Os tratamentos consistiram na aplicação de diferentes densidades de semeadura de duas cultivares de azevém anual (Barjumbo e BRS Ponteio): 12,5, 25, 50 e 75 $\mathrm{kg} / \mathrm{ha}$. Foram avaliados o número e altura de plantas, número de perfilhos por planta e massa seca de forragem. É fundamental a necessidade do controle externo de qualidade, executado pelo Estado, por meio da atividade fiscal, com vistas a garantir aos agricultores acesso a sementes de alta qualidade, o que tende a melhorar o estabelecimento inicial de pastagens de inverno. Em relação ao aumento gradativo da densidade de semeadura, constatou-se ganhos de produtividade em ambas as cultivares, com as sementes do cultivar Barjumbo apresentando melhor desempenho que as sementes do cultivar BRS Ponteio.

\section{Quality seeds of annual ryegrass and its impact on the initial establishment in different seedling densities}

\section{SUMMARY}

\section{ADDITIONAL KEYWORDS \\ Lolium multiflorum Lam. \\ Germination. \\ Purity. \\ Pasture management.}

\section{INFORMATION}

Cronología del artículo.

Recibido/Received: 28.11.2016

Aceptado/Accepted: 27.03 .2018

On-line: 15.04 .2018

Correspondencia a los autores/Contact e-mail:

guidoneda@yahoo.com.br
One of the problems involving the formation of winter pastures in Southern Brazil is the variation in the quality of forage seeds commercially available, resulting in the sale of low-quality seeds. In this sense, aimed to evaluate the quality of batches of annual ryegrass (Lolium multiflorum Lam.) marketed in the south of Santa Catarina (Brazil), in crops 2013, 2014, 2015 and 2016, as well as its effects on the initial establishment in different densities of seeding's. The collected seeds were derived from surplus sample of official collections of seeds collected by inspectors of State Agricultural authority in commercial establishments. Seed quality was evaluated as the response variable through physical purity, germination and number of other species of seeds. For evaluation of the initial establishment in sowing densities, an experimental design, was used in a randomized complete block in a factorial, $2 \times 4$, with four replications. The treatments consisted in the application of different seedling densities of two cultivars of annual ryegrass (Barjumbo and BRS Ponteio): 12.5, 25, 50 and $75 \mathrm{~kg} / \mathrm{ha}$. Were evaluated the number and plants height, tillers number per plant and dry matter forage. It is essential the need for external quality control, run by the State through fiscal activity, in order to ensure farmers access to high quality seeds, which tends to improve the initial establishment of winter pastures. The gradual increase in seeding rate provided productivity gains in both cultivars, with Barjumbo presenting better performance than BRS Ponteio.

\section{INTRODUÇÃO}

No Brasil, a atividade leiteira é praticada em todas as regiões e está presente em aproximadamente 1,8 milhões de propriedades rurais, das quais $80 \%$ são unidades familiares de produção (Ferrazza et al. 2015, p.
193). A pecuária de corte também tem forte representatividade ( $90 \%$ da carne produzida é com base em pastagens) (Ferraz \& Felício 2010, p. 238), sendo o maior exportador mundial de carne bovina e uma das principais atividades da economia nacional (Pandolfi Filho et al. 2016, p. 213). Dados do United States Department 
of Agriculture - USDA (2012) comprovam que o Brasil se posiciona como um dos principais fornecedores de alimentos para o mundo, inclusive proteína de origem animal, sendo o segundo maior produtor e exportador de carne e o quinto maior produtor de leite de bovinos.

Em Santa Catarina, o rebanho bovino obteve crescimento de $10 \%$ nos últimos oito anos, e representa atualmente $2 \%$ do rebanho brasileiro, com 4,28 milhões de cabeças (Empresa de Pesquisa Agropecuária e Extensão Rural de Santa Catarina [EPAGRI] 2015). Isto se deve, segundo Zanini et al. (2012, p. 1848), a sistemas de produção animal baseado em pastagens, a opção técnica que permite maior margem de flexibilidade na idealização e planejamento de sistemas competitivos e economicamente viáveis, uma vez que os custos de produção são baixos e o produto animal produzido é tido como de melhor qualidade.

Em regiões de clima subtropical como o sul do Brasil, o norte da Argentina e o Uruguai, a utilização de gramíneas hibernais para a implantação de pastagens cultivadas hibernais é muito comum (Amarilho-Silveira et al. 2016, p. 248), sendo que a o azevém anual (Lolium multiflorum Lam.) assume papel de destaque. Segundo Araújo et al. (2008, p. 61), nas últimas décadas, um grande número de informações foi gerado sobre gramíneas e leguminosas, contudo, este conhecimento recebeu pouca atenção por parte dos produtores. Segundo relatório de pesquisa fornecido pelo Serviço Brasileiro de Apoio às Micro e Pequenas Empresas - SEBRAE (2005), mais da metade dos produtores de carne do Rio Grande do Sul utilizam esta espécie para ser fornecida como alimento para os animais. De acordo com De Conto et al. (2011, p. 41), o azevém anual está plenamente adaptado às condições edafoclimáticas do Sul do Brasil, é bem aceito pelos animais, produz forragem de alto valor nutritivo (Gerdes et al. 2005, p. 1088), tolera o pisoteio e apresenta boa capacidade de rebrote (Pedroso et al. 2004, p. 1345). Contudo, segundo os mesmos autores, variações dos fatores bióticos e abióticos podem resultar em significativas mudanças na produção e na qualidade da forragem. Dentre os itens que compõem estes fatores, Marchi et al. (2010, p. 575) e Dos Santos et al. (2014, p. 55), comentam que o uso de lotes de sementes de baixa qualidade sanitária, sementes com resíduos excessivos de vegetais, resíduos do solo e/ou sementes de outras plantas forrageiras e plantas daninhas causam impacto negativo na produção de forragem e na qualidade para a implantação de pastagens. Segundo Schuch et al. (2008, p. 2), a produção de sementes de espécies forrageiras tem sido realizada muitas vezes por produtores não especializados, que não observam determinadas práticas agronômicas importantes para a obtenção de sementes de alta qualidade, o que acaba ocasionando variação na qualidade das sementes de espécies forrageiras disponíveis no comércio (Holbig et al. 2011, p. 71).

Dentre as práticas para obter sucesso na condução da pastagem, o manejo é uma das mais importantes, por modificar as características do pasto e favorecer seus estádios fenológicos (Barbosa et al. 2009, p. 389). Neste sentido, o uso de sementes de boa procedência é fator relevante na implantação da pastagem (Bevilaqua \& Pierobom 1995, p. 20) e a qualidade das sementes é essencial para o estabelecimento da cultura (Carvalho et al. 2016, p. 2; Ternus et al. 2016, p. 19). Segundo Argenta et al. (2001, p. 1076), a forma como as plantas são arranjadas influencia a captação por recursos importantes ao seu crescimento, como luz, água e nutrientes, portanto, a densidade de semeadura afeta a competição entre as plantas por recursos em razão da distribuição espacial, interferindo no rendimento final da cultura.

Diante do exposto, o objetivo deste estudo foi avaliar a qualidade fisiológica de lotes de sementes de azevém anual (Lolium multiflorum Lam.) comercializadas no Sul de Santa Catarina entre as safras de 2013 a 2016, bem como os impactos ocasionados pela qualidade das sementes em diferentes densidades de semeadura no estabelecimento inicial de duas cultivares (Barjumbo e BRS Ponteio) de azevém anual.

\section{MATERIAL E MÉTODOS}

O estudo para avaliar a qualidade física e fisiológica dos lotes de sementes de azevém anual (Lolium multiflorum Lam.) foi realizado no Laboratório Oficial de Análise de Sementes - LASO/SLAV, do Ministério da Agricultura, Pecuária e Abastecimento (MAPA) de São José, Santa Catarina, Brasil.

As sementes de azevém anual foram oriundas do excedente de coletas oficiais de amostra de sementes, realizada por Fiscal Estadual Agropecuário (FEA), a partir de amostragens realizadas em estabelecimentos comerciais e coletadas de acordo com metodologia prevista na Regra de Análise de Sementes (RAS) (Brasil 2009). No total, foram coletados 96 lotes de sementes de azevém anual comercializados com representatividade significativa em municípios do Sul de Santa Catarina (distribuídos conforme a Tabela I) durante as safras de 2013 a 2016. Para as avaliações da qualidade fisiológica das sementes foram realizados os testes de Pureza e Germinação. Na avaliação de pureza foi considerado o peso de cada lote e posteriormente separadas as sementes puras, as sementes de outras espécies (espécies cultivadas, silvestres, nocivas toleradas e proibidas

Tabela I. Lotes de sementes de azevém anual coletados durante as safras 2013, 2014, 2015 e 2016 em municípios do Sul do Estado de Santa Catarina (Ryegrass seeds lots collected during crops 2013, 2014, 2015 and 2016 districts in the Southern state of Santa Catarina).

\begin{tabular}{lcccc}
\hline $\begin{array}{l}\text { Municípios do } \\
\text { Sul de Santa } \\
\text { Catarina, Brasil }\end{array}$ & $\begin{array}{c}\text { Número de lotes de sementes de azevém } \\
\text { anual coletados }\end{array}$ \\
\cline { 2 - 5 } & 2013 & 2014 & 2015 & 2016 \\
\hline Braço do Norte & 11 & 9 & 12 & 7 \\
Rio Fortuna & 6 & 8 & 5 & 4 \\
Grão Pará & 5 & 6 & 7 & 3 \\
São Ludgero & 1 & 5 & 2 & 1 \\
Armazém & 1 & 2 & 1 & 0 \\
Total & 24 & 30 & 27 & 15 \\
\hline
\end{tabular}

Fonte: Dados da pesquisa (2016). 
foram determinadas por meio de identificação e contagem) e o material inerte. O resultado foi expresso em porcentagem de sementes puras do lote (Brasil 2009). Na avaliação de germinação as sementes foram semeadas em rolos de papel germitest, umedecido com água destilada na proporção de 2,5 vezes a massa do papel seco e mantidos em germinador regulado a $25^{\circ} \mathrm{C}$. A contagem de plântulas normais foi realizada aos 5 e 10 dias após a instalação do teste e os resultados expressos em porcentagem (Brasil 2009).

Para avaliar o efeito da qualidade das sementes em diferentes densidades de semeadura no estabelecimento inicial de duas cultivares de azevém anual foi realizado um experimento na comunidade de Baixo Pinheiral, com coordenadas geográficas de $28^{\circ} 13^{\prime} 18^{\prime \prime}$ de latitude Sul e 49 06'25.9" de longitude Oeste, localizado na zona rural do município de Braço do Norte, Sul do estado de Santa Catarina, Brasil. As duas cultivares de azevém anual (Barjumbo e BRS Ponteio) estudadas são bastante utilizadas na região Sul de Santa Catarina pelos pecuaristas, principalmente a BRS Ponteio, pelo valor comercial mais acessível das sementes.

O relevo da área é considerado suave a moderadamente ondulado e o solo classificado como Argissolo (Embrapa, 2013) de textura franco arenosa. As características químicas antes do início do período experimental estão demonstradas na Tabela II, conforme laudo expedido pelo Laboratório de Análise de Solos (LAS) da Empresa de Pesquisa Agropecuária e Extensão Rural de Santa Catarina (EPAGRI). Com base no resultado da análise de solo na camada de $0-20 \mathrm{~cm}$ não foi realizado nenhum tipo de correção química ao longo de todo o período experimental.

O delineamento experimental utilizado foi em blocos completos casualizados, em arranjo fatorial, $2 \mathrm{x}$ 4 (cultivar e densidades de semeadura), com 4 repetições, totalizando 32 unidades experimentais de $12 \mathrm{~m}^{2}$ cada, com área total de $384 \mathrm{~m}^{2}$.

A semeadura das duas cultivares (Barjumbo e BRS Ponteio) foi realizada em 13 de maio de 2016 utilizando-se 4 densidades de semeadura $(12,5,25,50$ e $75 \mathrm{~kg} /$ ha). A coleta de forragem foi realizada em 30 de junho de 2016, quando as plantas estavam com altura média de $35 \mathrm{~cm}$.

Para verificar os efeitos da densidade de semeadura foram analisadas as seguintes variáveis: altura de plantas $(\mathrm{cm})$, número de plantas por $\mathrm{m}^{2}$, número de perfilhos por planta e massa seca das plantas (kg/ ha). A altura do dossel foi determinada utilizandose um bastão medidor ("sward stick") em centímetros (Barthram 1985, p. 30) ao longo de 2 linhas transectas (5 pontos por transecta) em formato de ziguezague em cada unidade experimental. $\mathrm{O}$ número de plantas por $\mathrm{m}^{2}$ e o número de perfilhos por planta foi obtido por meio contagem de plantas utilizando-se uma armação quadrada de $25 \mathrm{~cm}^{2}$ de área. Para determinação da massa de forragem foram escolhidos 4 pontos representativos da condição média dos pastos no momento da avaliação, com o auxílio de uma armação de ferro quadrada com $25 \mathrm{~cm}^{2}$ de área. Nesses locais os perfilhos foram cortados no nível do solo e levados para estufas de circulação forçada de ar a $65^{\circ} \mathrm{C}$ durante 72 horas quando então, eram pesados para determinação da matéria seca (MS).

Em função da natureza do experimento, variáveis relacionadas a qualidade fisiológica das sementes, como pureza e germinação, foram mensurados como variáveis respostas. Variáveis obtidas por meio do delineamento experimental aplicado foram agrupados de acordo com as densidades de semeadura e cultivares utilizadas.

Os dados assim arranjados foram submetidos à análise de variância (ANOVA) por meio do pacote estatístico SISVAR® (Ferreira 2011, p. 1039-1042) versão 5.6 para Windows®. Dessa forma, foi possível detectar os efeitos das causas de variação principais (densidades de semeadura e cultivares utilizadas, bem como a interação entre elas). A comparação de médias foi realizada por meio do teste de Tukey, adotando-se o nível de significância de 5\%. Relações funcionais entre as densidades de semeadura e cultivares de azevém anual utilizadas com alturas do pasto, número de plantas por $\mathrm{m}^{2}$, número de perfilhos por planta e massa seca de forragem foram descritas por meio de recursos de regressões polinomiais do software de gráficos SigmaPlot $₫$ versão 11.0 para Windows ${ }^{\circledR}$.

\section{RESULTADOS E DISCUSSÃO}

Os lotes de sementes de azevém anual coletados durante as safras de 2013 a 2015 apresentaram, em média, pureza física abaixo do padrão mínimo exigido pela lei de comercialização de sementes, estabelecida pela Instrução Normativa $\mathrm{N}^{\circ} 25$ de 20 de dezembro de 2005 (Mapa 2005), na qual variou de 91,9 a 93,7\%, sendo que o padrão exigido por lei é de no mínimo 97\%. Já os lotes de sementes oriundos do ano de 2016, apresentaram média de pureza de 97,7\%. Apesar das safras de 2013, 2014 e 2015 apresentarem valores de pureza física abaixo do preconizado, observa-se uma evolução nos resultados ao longo dos anos em destaque, com a média dos lotes partindo em torno de 91\% no ano de 2013 para 97\% no ano de 2016 (Tabela III).

Com relação à germinação, observa-se que em todos os anos avaliados os lotes apresentaram-se abaixo do mínimo recomendado para comercialização (Tabela

Tabela II.Atributos químicos do Argissolo de textura franco arenosa utilizado no presente estudo (Chemical properties of sandy loam texture Argisol used in this study).

\begin{tabular}{lcccccccc}
\hline Argila & $\mathrm{pH} \mathrm{H}_{2} \mathrm{O}$ & $\mathrm{pH} \mathrm{SMP}$ & $\mathrm{P}$ & $\mathrm{K}$ & $\mathrm{Ca}$ & $\mathrm{Mg}$ & $\mathrm{Al}$ & $\mathrm{H}+\mathrm{Al}$ \\
\hline$\%$ & $1: 1$ & $1: 1: 0,5$ & \multicolumn{2}{c}{$\ldots \mathrm{mg} \mathrm{dm}^{-3} \ldots$} & & $\ldots \ldots \ldots \ldots \ldots \ldots \ldots \mathrm{cmol}_{\mathrm{c}} \mathrm{dm}^{-3} \ldots \ldots \ldots \ldots \ldots \ldots \ldots \ldots \ldots \ldots \ldots \ldots \ldots \ldots \ldots \ldots \ldots \ldots \ldots$ \\
24 & 5,8 & 6,5 & 34,9 & 444,0 & 2,9 & 3,0 & 0,0 & 2,5 \\
\hline
\end{tabular}

Fonte: Laboratório de Análise de Solos da Empresa de Pesquisa Agropecuária e Extensão Rural de Santa Catarina (EPAGRI). 
Tabela III. Valores médios de pureza física, germinação, outras sementes de espécies cultivadas, sementes silvestres, nocivas toleradas e proibidas de lotes de sementes de azevém coletados no Estado de Santa Catarina (Mean values of physical purity, germination, seeds of other cultivated species, wild seeds, tolerated and prohibited noxious lots of ryegrass seeds collected in the State of Santa Catarina).

\begin{tabular}{lcccc}
\hline \multirow{2}{*}{ Azevém anual } & \multicolumn{3}{c}{ Ano da coleta } \\
\cline { 2 - 5 } & 2013 & 2014 & 2015 & 2016 \\
\hline Pureza física (\%) & $91,9 \pm 6,1$ & $91,3 \pm 5,3$ & $93,7 \pm 4,1$ & $97,7 \pm 1,2$ \\
Germinação (\%) & $61 \pm 18$ & $60 \pm 18$ & $58 \pm 21$ & $57 \pm 15$ \\
Outras espécies cultivadas $\left(\mathrm{n}^{\circ}\right)$ & $17 \pm 17$ & $5 \pm 3$ & $15 \pm 14$ & $217 \pm 211$ \\
Sementes silvestres $\left(\mathrm{n}^{\circ}\right)$ & $5 \pm 4$ & $8 \pm 6$ & $2 \pm 2$ & $7 \pm 5$ \\
Sementes nocivas toleradas $\left(\mathrm{n}^{\circ}\right)$ & $4 \pm 4$ & $8 \pm 7$ & $26 \pm 23$ & $7 \pm 6$ \\
Sementes proibidas $\left(\mathrm{n}^{\circ}\right)$ & 0 & 0 & 0 & 0 \\
\hline
\end{tabular}

Fonte: Laboratório Oficial de Análise de Sementes do Ministério da Agricultura, Pecuária e Abastecimento (MAPA) de São José, Santa Catarina, Brasil.

III). Vale ressaltar que o teste padrão de germinação não é suficiente para a identificação precisa de lotes de diferentes níveis de qualidade. Deste modo, os testes de vigor tornam-se ferramentas cada vez mais rotineiras pela indústria de sementes para a determinação do potencial fisiológico e, dentre os testes mais utilizados, está o teste de emergência à campo (Ternus et al. 2016, p. 19). Então, lotes de sementes com baixa porcentagem de germinação, provavelmente, não formarão um estande adequado no campo. Ainda na tabela III, observa-se que apenas no ano de 2014 a média entre os lotes, em relação ao número de sementes de outras espécies cultivadas, permaneceu dentro dos padrões legais para sementes de azevém das categorias S1 e S2 (Mapa, 2005). Para o número de sementes silvestre, nocivas toleradas e proibidas (Tabela III), considerando apenas os padrões para as categorias S1 e S2, nota-se que a partir de 2014 os valores observados encontram-se dentro dos padrões exigidos por lei (Mapa, 2005).

O aumento do número de lotes de azevém inaptos para a comercialização no ano de 2016, principalmente pela baixa porcentagem de germinação e elevado número de outras espécies cultivadas, pode estar associado a rigorosidade do controle externo de qualidade do Estado de Santa Catarina. Ternus et al. (2016, p. 21) afirmam que a evolução do controle da qualidade na produção de sementes no Brasil, por meio do aprimoramento da legislação brasileira em torno da produção, análise laboratorial e comercialização de sementes de alta qualidade e de novas técnicas de produção desenvolvidas pela pesquisa pública e privada, caracteriza o esforço do controle externo de qualidade. Isto é de extrema relevância, pois, de acordo com Paiva et al. (2008, p. 131), a demanda por sementes de boa qualidade física, fisiológica e sanitária tem aumentado, principalmente para atender os rígidos padrões fitossanitários impostos por países importadores, o que tem motivado a competição entre produtores contribuindo para a melhoria da qualidade das sementes. Assim, durante todas as fases do processo de produção de sementes devem ser adotadas medidas para evitar contaminações genéticas ou varietais, colocando-se à disposição do agricultor sementes com as características desejadas (Ternus et al. 2016, p. 22).

Em relação as diferentes densidades de semeadura no estabelecimento inicial de cultivares de azevém anual, observa-se na Tabela IV maior número de plantas por $\mathrm{m}^{2}(\mathrm{P}<0,05)$, maior altura de plantas $(\mathrm{P}<0,05)$ e maior massa seca de forragem $(\mathrm{P}<0,05)$ do cultivar Barjumbo em relação a BRS Ponteio, independente da densidade de semeadura utilizada. Para o número de perfilhos por planta, não houve diferença significativa $(\mathrm{P}<0,05)$ entre os cultivares. Assim, é possível inferir que o cultivar Barjumbo possui maior capacidade de estabelecimento de suas plantas no campo em relação a BRS Ponteio. Este fato pode estar associado a características genéticas do cultivar Barjumbo, já que a mesma é originada de células reprodutivas de quantificação gênica tetraploide (Beskow, 2016). De acordo com o mesmo autor, são materiais contendo o dobro de cromossomos em cada célula (28), com relação aos diploides. Este fenômeno pode resultar tanto do cruzamento natural, como de cruzamento ou indução realizados pelo homem. Nas mesmas

Tabela IV. Número de plantas (NPL), altura de plantas (APL), número de perfilhos por planta (NPP) e massa seca das plantas (MSP) de duas cultivares de azevém cultivadas em diferentes densidades de semeadura. (Number of plants (NPP), plant height (APL), number of tillers per plant (NPP) and dry weight of plants (MSP) of two ryegrass cultivars in different sowing densities).

\begin{tabular}{lcccc}
\hline \multirow{2}{*}{ Cultivar } & \multicolumn{3}{c}{ Variáveis } \\
\cline { 2 - 5 } & $\mathrm{NPL}\left(\mathrm{m}^{2}\right)$ & $\mathrm{APL}(\mathrm{cm})$ & $\mathrm{NPP}$ & $\mathrm{MSP}\left(\mathrm{kg} \cdot \mathrm{ha}^{-1}\right)$ \\
\hline BRS Ponteio & $17,37 \mathrm{~b}$ & $28,57 \mathrm{~b}$ & $2,0 \mathrm{a}$ & $1.150 \mathrm{~b}$ \\
Barjumbo & $29,18 \mathrm{a}$ & $36,26 \mathrm{a}$ & $2,0 \mathrm{a}$ & $2.213 \mathrm{a}$ \\
CV $(\%)$ & 25,41 & 8,48 & 16,03 & 32,61 \\
\hline
\end{tabular}

Médias seguidas pela mesma letra na coluna não diferem entre si pelo teste de Tukey, a $5 \%$ de probabilidade. 

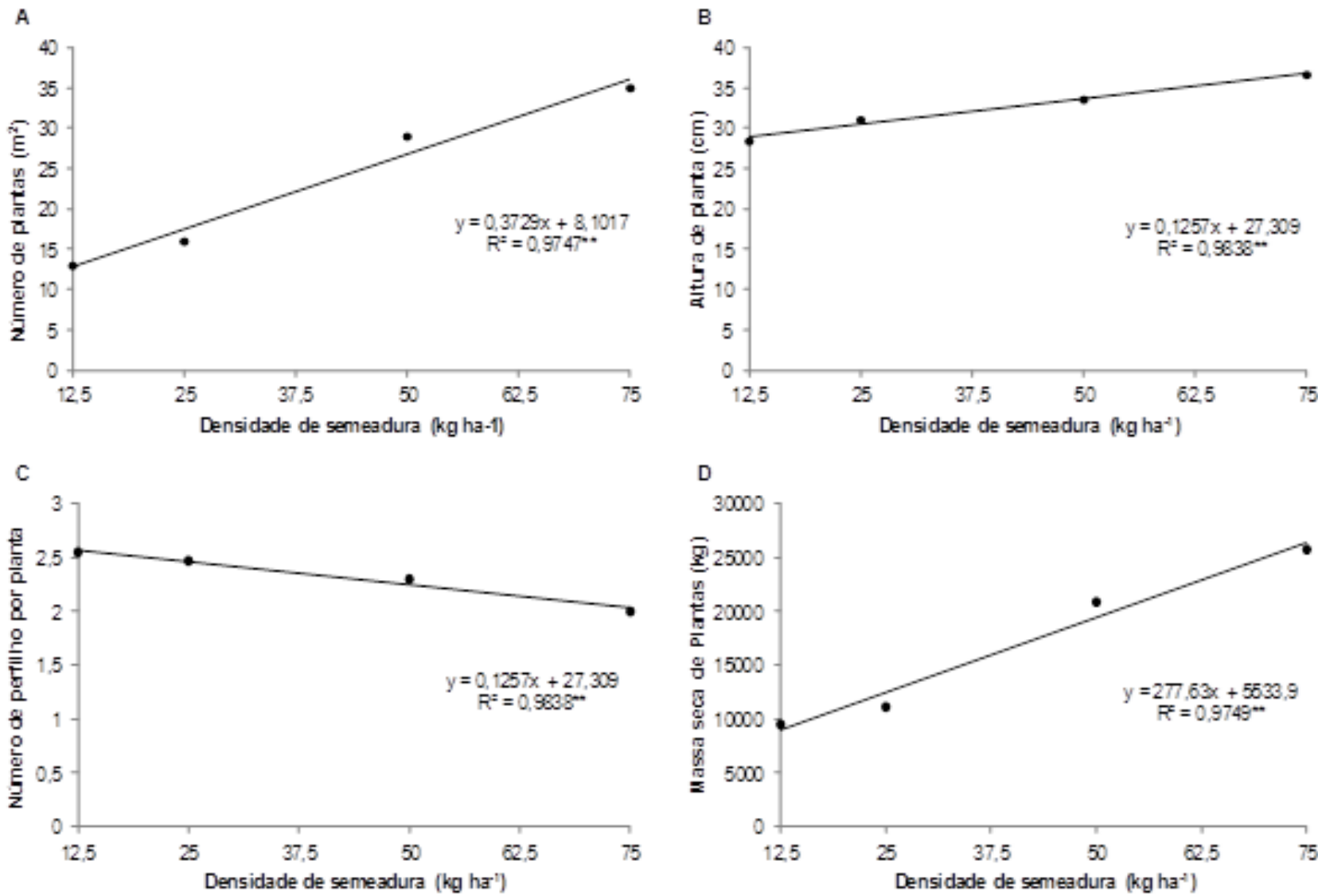

Figura 1. Número de plantas $\left(\mathrm{m}^{2}\right)$, altura de plantas $(\mathrm{cm})$, número de perfilhos por planta e massa seca de plantas $(\mathrm{kg})$ (Number of plants $\left(\mathrm{m}^{2}\right)$, plant height $(\mathrm{cm})$, number of tillers per plant and dry mass of plants $(\mathrm{kg})$.

condições de fertilidade (Tabela II) e manejo, as folhas dos tetraploides tendem a ser mais largas e cobrirem o solo mais completamente que os diploides. Além disso, segundo Blount et al. (2012, p. 2), cultivares tetraploides tem por característica maior produção de forragem (ver Tabela IV) e aparentam ser mais robustos que os diploides. No entanto, exigem fertilidade do solo mais acentuada para expressar seu potencial de crescimento (Sugiyama 2006, p. 156). As cultivares diploides, como a BRS Ponteio foram durante anos, o material mais utilizado pelos produtores, porém, o encurtamento do ciclo produtivo é um dos mais graves problemas observados nas áreas de cultivo, além da baixa qualidade dos lotes de sementes, o que diminui a disponibilidade de forragem. Por esta razão, genótipos de azevém anual têm sido estudados e selecionados na busca de materiais que, além de serem produtivos e de alta qualidade, tenham um ciclo produtivo mais longo (Beskow 2016, p. 1).

Constata-se na figura $\mathbf{1 A}$ e $\mathbf{1 B}$ que não houve interação $(\mathrm{P}<0,05)$ entre os cultivares e densidades de semeadura. No entanto, observa-se que o número de plantas por $\mathrm{m}^{2}$ e altura de plantas apresentou aumento gradativo linear crescente dessas características na medida em que se aumentou a densidade de semeadura.

Em relação ao número de perfilhos por planta, foi observado $(\mathrm{P}<0,05)$ redução de perfilhos conforme au- mento da densidade de semeadura (Figura 1C). Para a massa seca de forragem (Figura 1D), observa-se que não houve interação significativa $(\mathrm{P}<0,05)$ entre os fatores estudados. Contudo, foi observado comportamento semelhante ao verificado para as variáveis número de perfilhos por $\mathrm{m}^{2}$ e altura de plantas, ou seja, houve aumento gradativo linear crescente da massa seca de forragem na medida em que se aumentou a densidade de semeadura. As variações no número de perfilhos por planta foram causadas basicamente por oscilações sazonais nas taxas de aparecimento e morte de perfilhos, e refletem um efeito amplamente discutido e mostrado em pastos mantidos sob lotação contínua (Hernández-Garay et al. 1999, p. 350), segundo o qual a maior penetração de luz na base dos dosseis manejados mais baixos tende a estimular o perfilhamento. O efeito inverso é observado a partir do momento que começa a existir competição por luz, resultado direto da menor frequência de pastejo nos tratamentos com maior altura de entrada, quando, então, inicia-se processo de auto desbaste e a quantidade de perfilhos na área é reduzida (Yoda et al. 1963, p. 115). Portanto, as reduções no número de perfilhos por planta conforme o aumento da densidade de semeadura aqui apresentadas evidenciam claramente um mecanismo compensatório que tende a limitar a população de perfilhos numa dada condição, ou seja, com o objetivo de compensar uma redução nas taxas de aparecimento, 
os perfilhos tendem a sobreviver por mais tempo afim de manter estável a população de plantas e garantir sua persistência na área (Parsons \& Chapman 2000, p. 43).

\section{CONCLUSÕES}

Percebe-se uma evolução na melhoria da qualidade dos lotes de sementes de azevém anual comercializados durante o período avaliado. Neste sentido, fica evidente a importância do controle externo de qualidade por meio da atividade fiscal. Estas ações, executadas de maneira organizada, garante aos agricultores o acesso a sementes de qualidade superior, favorecendo o desempenho das cultivares, diminuindo os custos de produção em função da redução da densidade de semeadura, além de maximizar a produtividade dos pastos cultivados no Sul do Brasil.

Individualmente, o cultivar Barjumbo apresenta melhor desempenho que o BRS Ponteio.

\section{BIBLIOGRAFIA}

Amarilho-Silveira, F, Vicente, IS, Lemes, JS, Del Pino, FAB, Esteves, RM, Halfen, J, Tâmara, QJ, Da Vara, CC \& Mattei, P 2016. 'Ganho de peso, níveis de glicose sanguínea e qualidade da lã de ovelhas manejadas no terço final de gestação em pastagens hibernais'. Archivos de Zootecnia, vol. 65 (250): 247-251.

Araújo, SAC, Deminicis, BB \& Campos, PRSS 2008, 'Melhoramento genético de plantas forrageiras tropicais no Brasil', Archivos de Zootecnia, vol. 57, pp. 61-76.

Argenta, G, Silva, PRF \& Sangoi, L 2001, 'Arranjo de plantas em milho: análise do estado-da-arte', Ciência Rural, vol. 31, pp. 1075-1084.

Barthram, GT 1985, 'Experimental techniques: the HFRO sward stick', in Biennial report, Penicuik, Proceedings of the Hill Farming Research Organization, HFRO, pp. 29-30.

Barbosa, CMP, Carvalho, PCF, Cauduro, GF, Devincenzi, T, Nabinger, C \& Jacques, AVA 2009, 'Efeito de métodos e intensidades de pastejo sobre a ressemeadura natural de azevém anual', Acta Scientiarum Animal Science, vol. 30, pp. 388-393.

Beskow, W 2016, 'Tipos de azevéns e suas particularidades', in Boletim Técnico Transpondo, Pesquisa, Treinamento e Consultoria Agropecuária Ltda, Rio Grande do Sul, RS, pp. 1-2.

Bevilaqua, GAP \& Pierobom, CR 1995, 'Qualidade sanitária e fisiológica de sementes de aveia preta (Avena strigosa Schreb) da Zona Sul Do Rio Grande Do Sul', Revista Brasileira de Sementes, vol. 17, pp. 22-19.

Blount, AR, Prine, GM \& Chambliss, CG 2012, 'Annual ryegrass, Tampa's: Agronomy Department, Florida Cooperative Extension Service', Institute of Food and Agricultural Sciences, University of Florida, pp. 1-3.

Brasil 2009, Regras para análise de sementes, Ministério da Agricultura, Pecuária e Abastecimento, MAPA, Brasília, DF, 399 p.

Carvalho, TB, Zen, S \& Tavares, ECN 2009, Comparação de custo de produção na atividade de pecuária de engorda nos principais países produtores de carne bovina, in Sociedade Brasileira de Economia, Administração e Sociologia Rural, Anais do $47^{\circ}$ Congresso da Sociedade brasileira de Economia, Administração e Sociologia Rural, Porto Alegre, RS, pp. 01-18.

De Conto, L, Sganzerla, DC, Pedroso, CES \& Monks, PL 201 1, 'Relação azevém anual (Lolium multiflorum Lam.) - Ruminante', Archivos de Zootecnia, vol. 60, pp. 41-54.

Dos Santos, GR, Tschoeke, PH, Silva, LG, Da Silveira, MCAC, Reis, HB, Brito, DR \& Carlos, DS 2014, 'Sanitary analysis, transmission and pathogenicity of fungi associated with forage plant seeds in tropical regions of Brazil', Journal of Seed Science, vol. 36, pp. 054-062.
Empresa Brasileira de Pesquisa Agropecuária 2013, Sistema Brasileiro de Classificação do Solo - SIBCS 2013, EMBRAPA, Brasília, DF, 353 p. Empresa de Pesquisa Agropecuária e Extensão Rural de Santa Catarina 2015, Síntese Anual da Agricultura de Santa Catarina 2014-2015, EPAGRI/CEPA, Florianópolis, SC, 156 p.

Ferraz, JBS \& Felício, PED 2010, 'Production systems - an example from Brazil', Meat Science, vol. 84, pp. 243-238.

Ferrazza, RA, Lopes, MA, Bruhn, FRP \& De Moraes, F 2015, 'Índices de desempenho zootécnico e econômico de sistemas de produção de leite com diferentes tipos de mão de obra', Ciência Animal brasileira, vol. 16, pp. 193-204.

Ferreira, DF 2011 , 'Sisvar: a computer statistical analysis system', Ciência e Agrotecnologia (UFLA), vol. 35, pp. 1042-1039.

Gerdes, L, De Mattos, HB, Werner, JC, Colozza, MT, Dos Santos, LE, Da Cunha, EA, Bueno, MS \& Schammass, EA 2005, 'Características do dossel forrageiro e acúmulo de forragem em pastagem irrigada de capim-aruana exclusivo ou sobressemeado com uma mistura de espécies forrageiras de inverno', Revista Brasileira de Zootecnia, vol. 34, pp. 1088-1097.

Hernández-Garay, A, Matthew, C \& Hodgson, J 1999, 'Tiller size/ density compensation in perennial ryegrass miniature swards subject to differing defoliation heights and a proposed productivity index', Grass and Forage Science, vol. 54, pp. 347-356.

Holbig, LS, Harter, FS, Galina, S, Deuner, C \& Villela, FA 2011, 'Diferenças na qualidade física e fisiológica de sementes de aveia preta e azevém comercializadas em duas regiões do Rio Grande do Sul', Revista da FZVA, vol. 8, pp. 70-80.

Marchi, CE, Fernandes, CD, Bueno, ML Batista, MV \& Fabris, LR 2010, 'Microflora fúngica de sementes comerciais de Panicum maximum e Stylosanthes spp', Semina Ciências Agrárias, vol. 31, pp. 575-584.

Ministério da Agricultura, Pecuária e Abastecimento 2005, Departamento Nacional de Defesa Vegetal, MAPA, Brasilia, DF.

Paiva, AS, Rodrigues, TJD, Cancian, AJ, Lopes, MM \& Fernandes, AC 2008, 'Qualidade de sementes

de macrotiloma (Macrotyloma axillare) Cv. Java', Revista Brasileira de Sementes, vol. 30, pp. 130-136.

Pandolfi Filho, AD, Do Valle, CB, Barrios, SCL, Alves, GF \& Deminicis, BB 2016. 'Avaliação de

genitoras sexuais de Brachiaria spp. na época de seca'. Archivos de Zootecnia, vol 65, pp 213-219.

Parsons, AJ \& Chapman, HDF 2000, 'The principles of pasture growth and utilization', in Hopkins A. (ed) Grass: Its Production and Utilization, Oxford: Blackwell Science for the British, Grassland Society, pp. 31-89.

Pedroso, CES, De Medeiros, RB, Da Silva, MA, Da Jornada, JBJ, De Saibro, JC \& Teixeira, JRF 2004, 'Produção de ovinos em gestação e lactação sob pastejo em diferentes estádios fenológicos de azevém

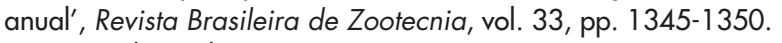

Serviço Brasileiro de Apoio às Micro e Pequenas Empresas 2005, Diagnóstico de sistemas de produção da bovinocultura de corte do Estado do Rio Grande do Sul, SEBRAE/SENAR/FARSUL, Porto Alegre, RS, $265 \mathrm{p}$.

Schuch, LOB, Kolchinski, EM \& Cantarelli, LD 2008, 'Relação entre a qualidade de sementes de aveia preta e a produção de forragem e de sementes', Scientia Agraria, vol. 9, pp. 1-6.

Sugiyama, S 2006, 'Responses of shoot growth and survival to water stress gradient in diploid and tetraploid populations of Lolium multiflorum and L. perenne', Grasslands Science, vol. 52, pp. 160-155.

United States Department of Agriculture 2012, Dairy: World Markets and Trade, USDA. Disponível em: http://www.fas.usda.gov/psdonline/ circulars/dairy.pdf. [Acesso em: 14 set. 2016].

Ternus, RM, Meneghello, G, Breda, ML \& Cavalcante, JA 2016, 'O controle externo de qualidade na comercialização de sementes', Seed News, vol. 20, pp. 18-23.

Yoda, K, Kira, T, Ogawa, H, \& Hozumi, H 1963, 'Intraspecific competition among higher plants, XI Selfthinningin overcrowded pure stands under cultivate and natural conditions', Journal of Osaka City University Institute of Polytechnics, vol. 14, pp. 107-129. 
Zanini, GD, Santos, GT \& Sbrissia, AF 2012, 'Frequencies and intensities of defoliation in Aruana guineagrass swards: morphogenetic and structural characteristics ${ }^{1}$, Revista Brasileira de Zootecnia, vol. 41 , pp. 1848-1857.
Zoccal, R \& Gomes, AT 2004, 'O agronegócio do leite: análise e perspectivas', Anais do $47^{\circ}$ Congresso Brasileiro de Economia e Sociologia Rural, Cuiabá, Brasil, pp. 1-3. 